\title{
Neurological Diseases, Disorders and Injuries in Canada: Highlights of a National Study
}

\author{
Garth M. Bray, Deanna L. Huggett
}

\begin{abstract}
The National Population Health Study of Neurological Conditions, a partnership between Neurological Health Charities Canada and the Government of Canada, was the largest study of neurological diseases, disorders, and injuries ever conducted in Canada. Undertaken between 2009 and 2013, the expansive program of research addressed the epidemiology, impacts, health services, and risk factors of 18 neurological conditions and estimated the health outcomes and costs of these conditions in Canada through 2031. This review summarizes highlights from the component projects of the study as presented in the synthesis report, Mapping Connections: An Understanding of Neurological Conditions in Canada. The key findings included new prevalence and incidence estimates, documentation of the diverse and often debilitating effects of neurological conditions, and identification of the utilization, economic costs, and current limitations of related health services. The study findings will support health charities, governments, and other stakeholders to reduce the impact of neurological conditions in Canada.
\end{abstract}

RÉSUMÉ: Faits saillants d'une étude nationale canadienne sur les maladies, affections et traumatismes neurologiques. L'Étude nationale de la santé des populations relative aux maladies neurologiques, un partenariat entre les Organismes caritatifs neurologiques du Canada et le Gouvernement du Canada, constitue la plus grande étude sur les maladies, les affections et les traumatismes neurologiques jamais effectuée au Canada. Réalisé entre 2009 et 2013, cet important programme de recherche a étudié l'épidémiologie, les impacts, les services de santé et les facteurs de risque de 18 pathologies neurologiques et a estimé l'incidence sur la santé et les coûts de ces pathologies au Canada jusqu'en 2031. Cette revue présente un sommaire des faits saillants des différents volets du projet tels que présentés dans le rapport de synthèse intitulé: Établir les connexions: Mieux comprendre les affections neurologiques au Canada. Les faits saillants de ce rapport sont les suivants: de nouveaux estimés de la prévalence et de l'incidence de ces pathologies, la documentation des effets divers et souvent débilitants des problèmes neurologiques, ainsi que l'identification de l'utilisation des coûts économiques et des limites actuelles des services de santé qui y sont consacrés. Les observations de cette étude permettront de soutenir des organismes de bienfaisance dans le domaine de la santé, les gouvernements ainsi que d'autres parties prenantes, afin de diminuer l'impact des pathologies neurologiques au Canada.

Keywords: Clinical epidemiology, epidemiology, health services research, quality of care, quality of life

doi:10.1017/cjn.2015.312

Can J Neurol Sci. 2016; 43: 5-14

\section{INTRODUCTION}

The National Population Health Study of Neurological Conditions ("the study") was a 4-year investigation of the human and economic impacts of diseases, disorders, and injuries of the nervous system (hereafter "neurological conditions") in Canada. Initiated in $2009^{1}$ as a partnership involving Neurological Health Charities Canada, ${ }^{2}$ the Public Health Agency of Canada, ${ }^{3}$ Health Canada, and the Canadian Institutes of Health Research, the study consisted of 13 research projects, three national surveys, a microsimulation project that modeled the scope and impacts of seven neurological conditions between 2011 and 2031, and an expansion of the Canadian Chronic Disease Surveillance System. The final report, Mapping Connections: An Understanding of Neurological Conditions in Canada, ${ }^{4}$ which was released by the federal Minister of Health in September 2014, integrates a synthesis of the scientific results of the study by an external panel of experts (called the Synthesis Panel) with the insights of people with neurological conditions, caregivers, and other stakeholders.

To varying extents, the study projects investigated 18 neurological conditions (Table 1), including their epidemiology (prevalence and incidence), impacts (on affected individuals, families, caregivers, and communities), associated risk factors, and related health services utilization. Many of the findings represent new information that was not previously available in a Canadian context. This review highlights the utility of select findings from the study pertaining to the prevalence and impact of neurological conditions and related health services. Additional information,

From the Departments of Medicine and of Neurology \& Neurosurgery, McGill University, Montreal, Quebec, Canada (GMB, Professor Emeritus); and Neurological Health Charities

Canada, Toronto, Ontario, Canada (DLH, former director, Strategic Initiatives). Received January 21, 2015. Final Revisions Submitted May 12, 2015 Correspondence to: Garth M. Bray, 109 - 205 Somerset Street West Ottawa, Ontario K2P 0J1, Canada. E-mail: garth.m.bray@mcgill.ca 
Table 1: Diseases, disorders, and injuries studied in the National Population Health Study of Neurological Conditions*

\begin{tabular}{l|l|l}
\hline $\begin{array}{c}\text { Amyotrophic lateral } \\
\text { sclerosis }\end{array}$ & Huntington disease & Spina bifida \\
\hline Brain tumours & Hydrocephalus & Spinal cord tumours \\
\hline Cerebral palsy & Migraine & Stroke \\
\hline $\begin{array}{l}\text { Dementia including } \\
\text { Alzheimer disease }\end{array}$ & Multiple sclerosis & Tourette syndrome \\
\hline Dystonia & Muscular dystrophy & Traumatic brain injury \\
\hline Epilepsy & Parkinson disease & Traumatic spinal cord injury \\
\hline
\end{tabular}

*Some study projects investigated the more prevalent conditions only.

including more detailed accounts of the methodology of the study, its component projects and surveys, and their principal investigators, can be found in Mapping Connections. ${ }^{4,5}$ Many of the study researchers have also produced peer-reviewed publications related to their specific projects. ${ }^{6}$

\section{Epidemiology of Neurological Conditions in Canada}

Reliable epidemiological data, including estimates of prevalence (extent of the population affected) and incidence (new occurrences), are the basis for rational health care policy and planning, but few Canadian epidemiological studies were identified in a systematic review of the published literature. ${ }^{7}$ To address this gap, several projects investigated the prevalence and incidence of neurological conditions in Canada. These projects used different data sources-systematic reviews and meta-analyses of published estimates that met predetermined criteria for quality and homogeneity, ${ }^{7}$ health administrative databases, electronic medical records (EMRs), surveys, and microsimulation models-each of which has strengths and weaknesses. The most reliable ${ }^{8}$ new estimates of Canadian prevalence or incidence were considered to be those that were within, or their $95 \%$ confidence intervals overlapped with, the $95 \%$ confidence intervals of the metaanalyses ${ }^{7}$ of published studies (mostly from outside of Canada) or were confirmed by more than one source.

\section{Estimates of Prevalence and Incidence}

New Canadian prevalence estimates of select neurological conditions, ranked according to their level of reliability, ${ }^{8}$ are shown in Table 2. Additional information can be found in Mapping Connections, Table $3-1 .^{9}$ Other projects documented the high prevalence of neurological conditions among Canadians living in long-term care facilities (see Mapping Connections, Table 3-2 ${ }^{10}$; Mapping Connections, Components 8, $17^{5}$ ).

The project based on the Canadian Community Health Surveys (CCHS) 2010-2011 (Mapping Connections, Component $3^{5}$ ) was the only study component that provided data for all provinces and territories. ${ }^{9}$ Although prevalence estimates from the other projects may not be strictly applicable to all Canadian jurisdictions, they can be considered reasonable approximations. Moreover, their validity supports the application of their methodology to other provinces and territories, as is being done by the expanded Canadian Chronic Disease Surveillance System. ${ }^{11}$
The Microsimulation Project (Mapping Connections, Component $10^{5}$ ) used the platform for Statistics Canada's Population Health Model and data from several projects of the study to predict the incidence and prevalence over a 20-year period (2011-2031) of seven neurological conditions: cerebral palsy, dementia, epilepsy, multiple sclerosis, Parkinson disease, hospitalized traumatic brain injury, and hospitalized spinal cord injury. ${ }^{12}$ Microsimulation modelling projected that, by 2031, the incidence rates for dementia and Parkinson disease will increase by nearly $50 \%$ and the number of hospitalizations related to traumatic brain injury will increase by $28 \% .{ }^{13}$ In addition, the prevalence of each of the seven modelled conditions will double. ${ }^{14}$ These projected increases could be reduced if new or improved prevention strategies are discovered and implemented.

The study also provided useful methodological information about the utility and limitations of different sources of epidemiological data:

- Case definitions for dementia, epilepsy, multiple sclerosis, and parkinsonism, which were validated using an Ontario database that links data from electronic medical records to administrative data (Mapping Connections, Component $12^{5}$ ), produced prevalence estimates for dementia, parkinsonism, and multiple sclerosis that were congruent with the estimates shown in Table 2. These case definitions were also used to expand the Canadian Chronic Disease Surveillance System (Mapping Connections, Component $2^{5}$ ), thereby contributing to the ongoing collection of data on neurological conditions at the national level.

- The pan-Canadian self-report survey produced prevalence estimates that had varying levels of reliability. ${ }^{9}$ For example, compared with the estimates based on meta-analysis or administrative data, the self-reported survey data produced a lower prevalence estimate for dementia, even though the survey accepted proxy responses. - EMRs from a network of family physicians (Mapping Connections, Component $6^{5}$ ) yielded prevalence estimates for dementia, epilepsy, and parkinsonism that were congruent with the estimates from the meta-analyses. ${ }^{7}$ Thus, EMRs could be another source of readily accessible epidemiological data if they could identify other neurological conditions as efficiently as the three conditions investigated.

- Diagnostic specificity can be limited if databases are used that do not include the complete five-digit International Classification of Diseases codes. This occurred in some projects of the study that relied on physician claims data that only capture a broad category of disorder (e.g. parkinsonism instead of Parkinson disease, anterior horn cell disease instead of amyotrophic lateral sclerosis, or myopathy instead of muscular dystrophy).

- Health data registries are recommended for less prevalent neurological conditions such as amyotrophic lateral sclerosis (Mapping Connections, Component $\left.18^{5}\right) .^{7}$ To this end, one study project (Mapping Connections, Component $15^{5}$ ) validated guidelines for the development and maintenance of registries. ${ }^{15}$ These guidelines have already facilitated the development of a new Canadian registry for Rett syndrome. ${ }^{16}$

The epidemiological projects of the study provided a new level of understanding of the scope of neurological conditions in Canada. Although not all of the 18 neurological conditions were investigated to the same extent, the availability of Canadian data on the more prevalent conditions is an advance that will support policy development and programming as well as data and methodological information for future research efforts. For the age 
Table 2: Prevalence* of neurological conditions in Canada ${ }^{\dagger, *}$ compared with results of meta-analyses $^{\S}$



$\mathrm{CI}=$ confidence interval.

*Mapping Connections, Table $3-1^{9}$ should be consulted for more detailed information about each of these estimates, including case definitions and data from the meta-analyses.

${ }^{\dagger}$ British Columbia administrative data. ${ }^{9}$

${ }^{\dagger}$ Pan-Canadian self-report survey data. ${ }^{9}$

${ }^{\S}$ Systematic review and meta-analysis data (Mapping Connections, Component $18^{5}$ ). ${ }^{7}$

"For a discussion of degrees of reliability of prevalence estimates, see Mapping Connections, page $52 .{ }^{8}$

"Case definition used diagnostic code for "anterior horn cell disease."

"Interpret with caution; coefficient of variation between $16.6 \%$ and $33.3 \%$.

**Case definition used diagnostic code for "myopathy."

${ }^{\dagger}$ Case definition used diagnostic code for "parkinsonism."

group 45 years and older, prevalence and incidence data will eventually become available from the Canadian Longitudinal Study of Aging, which, as part of the study, added dementia, epilepsy, Parkinson disease, and traumatic brain injury to its longterm surveillance project (Mapping Connections, Component $5^{5}$ ).

\section{IMPACT OF NeUROLOGical CONDITIONS}

The study provided extensive information on the diverse and often debilitating impacts of neurological conditions. Although the impacts of specific neurological deficits will be intuitively 
obvious to clinicians, their documentation is important information for policy-makers, health care planners, and researchers. The study also documented nonclinical impacts that are equally important to appreciate because they present significant challenges to quality of life.

Two projects used survey data to document the extent and intensity of impacts of neurological conditions on individuals, families and caregivers. The Survey on Living with a Neurological Condition in Canada (SLNCC) (Mapping Connections, Component $16^{5}$ ) involved structured interviews with 4,409 Canadians or their proxy respondents who had indicated in the 2010 and 2011 CCHS that they, or a household member, had one of the 18 targeted conditions. The proportions of proxy responses ranged from $3.8 \%$ for multiple sclerosis to $76.5 \%$ for dementia. When transposed to the Canadian population using Statistics Canada population weights, this sample represented approximately 1,738,000 private household residents with a neurological condition. Results were reported for all 18 neurological conditions together and for individual conditions if they fulfilled Statistics Canada's criteria concerning numbers of observations and variances. For each condition, the proportions, but not actual numbers, of observations were reported by the SLNCC project team.

The Everyday Experience of Living with and Managing a Neurological Condition (LINC) Project (Mapping Connections, Component $9^{5}$ ) consisted of three nested studies: (1) a volunteer survey of 754 individuals and 74 parents of children with a neurological condition; (2) more detailed interviews with 134 of these individuals; and (3) in-depth case studies of 21 of these same individuals and 55 support persons. Data for the LINC participants were compared with data from the CCHS 2009-2010 for "all Canadians" or those with one or more "other chronic" conditions. Although based on smaller samples, most of the LINC survey findings were concordant with those of the SLNCC.

These studies documented that neurological conditions:

- impair general health and affect ability to function. Compared with age-matched controls, more Canadians with a neurological condition described their general health as "poor" or "fair", ${ }^{17}$ reported limitations of usual activities or were permanently unable to work (Table 3).

- affect mental health. Greater proportions of Canadians with a neurological condition also reported high levels of stress or having been diagnosed with a mood or anxiety disorder (Table 3).
Depending on the condition, $17.1 \%$ to $38.3 \%$ of adults with a neurological condition reported a coexisting mood disorder (Table 4).

- cause perceptions of stigmatization. Depending on the condition, $5 \%$ to $36 \%$ of Canadians age 15 years and older with a neurological condition felt left out of activities, embarrassed by their condition, or perceived that others felt uncomfortable around them or avoided them.

- limit ability to work. The percentage of adults with a neurological condition who were permanently unable to work ranged from less than $20 \%$ for those with migraine or epilepsy to nearly $50 \%$ for those with dementia, Parkinson disease, or muscular dystrophy. ${ }^{18}$ Limited ability to work could be a contributing factor in financial insecurity for people affected by neurological conditions. In fact, approximately $35 \%$ of the LINC survey respondents reported that their family had experienced a financial crisis in the previous year, and $14 \%$ of those who were employed reported a demotion or pay cut.

- cause cognitive impairment. Predictably, individuals with dementia had the highest prevalence of self- or proxy-reported cognitive impairment (93.7\%). However, among those with other neurological conditions, $35 \%$ (migraine) to $68 \%$ (traumatic brain injury) acknowledged memory impairment and $18 \%$ (migraine) to $60 \%$ (cerebral palsy) reported difficulty thinking and problem solving. ${ }^{19}$ - cause pain and discomfort. Approximately 30\% of the Canadian population living with a neurological condition reported moderate or severe pain, with $10 \%$ overall reporting pain that prevented most activities. Such severe pain was reported by $36.6 \%$ of individuals with traumatic spinal cord injury. ${ }^{20}$

- impair quality of life. The Health Utilities Index (HUI) is a validated system that relates severity of disability and quality of life by incorporating ratings assigned to eight functional categories (cognition, emotion, speech, vision, hearing, dexterity, mobility, and pain and discomfort) into a global score. ${ }^{21}$ For ten of the targeted neurological conditions (Table 5), the mean global HUI-3 score was less than 0.7 , which represents severe disability. ${ }^{22}$ The score for migraine corresponded to a moderate level of disability.

Using models that accounted for future changes in the Canadian population but not for possible improvements in prevention, diagnosis, treatment or management of the conditions, the Microsimulation Project estimated that, by 2031, more Canadians living with the seven modelled neurological conditions (cerebral palsy, dementia, epilepsy, multiple sclerosis, Parkinson disease, traumatic brain injury and traumatic spinal cord injury) will

Table 3: Impacts of neurological conditions on health and daily activities, Canada*

\begin{tabular}{l|c|c|c}
\hline & All 18 NCs & Migraine excluded & Age-matched Canadians without NCs \\
\hline General health: "fair" or "poor"-all NCs ${ }^{\dagger}$ & $25.4 \%$ & $46.2 \%$ & $10.2 \%$ \\
\hline Most days "quite a bit" or "extremely" stressful & $34.9 \%$ & & $22.0 \%$ \\
\hline Diagnosed with a mood or anxiety disorder & $22.6 \%$ & & $8.6 \%$ \\
\hline Limitations of usual activities & $50.6 \%$ & $76.9 \%$ & $26.7 \%$ \\
\hline Permanently unable to work (age 18-64) & $8.1 \%$ & $25.4 \%$ & $1.7 \%$ \\
\hline
\end{tabular}

$\mathrm{NC}=$ neurological condition.

*Source: Survey on Living with a Neurological Condition in Canada 2011-2012.

${ }^{\dagger}$ Source: Canadian Community Health Surveys 2010-2011.

${ }^{\ddagger}$ General health by specific neurological condition is shown in Mapping Connections, page 17, Figure 1-1. ${ }^{17}$ 
Table 4: Mood disorders among respondents age 15+ years, Canada, 2011-2012, SLNCC*

\begin{tabular}{l|c|c}
\hline & \multicolumn{2}{|c}{ Prevalence of mood disorder $^{\dagger}$} \\
\hline Neurological condition $^{\dagger}$ & Mean (\%) & 95\% Confidence interval \\
\hline All neurological conditions & 23.0 & $19.5-26.5$ \\
\hline Brain injury (traumatic) & 38.3 & $29.5-47.0$ \\
\hline Brain tumour & $35.5^{\S}$ & $23.2-47.9^{\S}$ \\
\hline Cerebral palsy & $20.4^{\S}$ & $9.2-31.7^{\S}$ \\
\hline Demential & 29.7 & $22.5-36.8$ \\
\hline Epilepsy & 17.1 & $12.1-22.0$ \\
\hline Migraine & 24.9 & $19.1-30.7$ \\
\hline Multiple sclerosis & 22.5 & $16.0-28.9$ \\
\hline Parkinson disease & 22.5 & $15.2-29.9$ \\
\hline Spina bifida & $19.3^{\S}$ & $9.1-29.6^{\S}$ \\
\hline Spinal cord injury (traumatic) & 29.2 & $22.3-36.2$ \\
\hline Stroke & 23.0 & $17.6-28.4$ \\
\hline Tourette syndrome & $25.1^{\S}$ & $9.9-40.3^{\S}$ \\
\hline
\end{tabular}

SLNCC $=$ Survey on Living with a Neurological Condition in Canada.

*Source: Mapping Connections, Figure 1-2, page 18.

${ }^{\dagger}$ Self-reported, professionally diagnosed, lasting 6 months

or more.

${ }^{\ddagger}$ Sample sizes for amyotrophic lateral sclerosis, dystonia, Huntington disease, hydrocephalus, muscular dystrophy, and spinal cord tumour were too small to report.

"Alzheimer disease and other dementias.

${ }^{\S}$ Interpret with caution; coefficient of variation between $16.6 \%$ and $33.3 \%$.

experience severe disability (as defined by HUI-3 scores), and affected individuals born during the current decade will lose (depending on the condition) 14 to 41 equivalent years of life living in full health. ${ }^{23}$

Indirect costs, calculated from average income lost because of premature death and disability among working-age Canadians, are another measure of the impact of neurological conditions. The Microsimulation Project documented that, among the seven conditions investigated, indirect costs in 2011 were greatest for epilepsy, multiple sclerosis, and traumatic brain injuryconditions that predominantly affect working-age adults. By 2031, total indirect economic costs related to neurological conditions are projected to increase as the result of an increase in working age disability (Table 6).

In addition to documenting the range and extent of the impacts of neurological conditions, the study's findings concluded that, irrespective of diagnosis, different conditions affect individuals and families in many similar ways. This conclusion provides an impetus for the neurological community to address shared challenges through collaboration and collective action.

\section{Impacts on Children}

The information gleaned from the study about the impact of neurological conditions on children was limited and noted as an area requiring further investigation. However, the LINC Project survey of 74 parents and subsequent interviews with 47 parents from
Table 5: HUI-3 Global scores for neurological conditions respondents age 15+ years, Canada, 2011-2012, SLNCC*

\begin{tabular}{|c|c|c|c|}
\hline \multirow[b]{2}{*}{ Neurological condition } & \multicolumn{2}{|c|}{$\begin{array}{c}\text { Overall HUI-3 } \\
\text { score }^{\dagger}\end{array}$} & \multirow[b]{2}{*}{$\begin{array}{c}\text { Proportion with } \\
\text { "severe" or } \\
\text { "moderate" disability }\end{array}$} \\
\hline & Mean & $\begin{array}{c}95 \% \\
\text { confidence } \\
\text { interval }\end{array}$ & \\
\hline Amyotrophic lateral sclerosis & $\$$ & $\S$ & $\S$ \\
\hline Brain injury (traumatic) & 0.52 & $0.46-0.58$ & $74 \%$ \\
\hline Brain tumour & 0.57 & $0.49-0.66$ & $77 \%$ \\
\hline Cerebral palsy & 0.49 & $0.35-0.64$ & $82 \%$ \\
\hline Dementia" & 0.21 & $0.15-0.26$ & $95 \%$ \\
\hline Dystonia & 0.64 & $0.54-0.74$ & $\S$ \\
\hline Epilepsy & 0.67 & $0.62-0.72$ & $60 \%$ \\
\hline Huntington disease & $\$$ & $\$$ & $\S$ \\
\hline Hydrocephalus & 0.63 & $0.52-0.74$ & $\S$ \\
\hline Migraine & 0.79 & $0.76-0.83$ & $42 \%$ \\
\hline Multiple sclerosis & 0.55 & $0.50-0.61$ & $76 \%$ \\
\hline Muscular dystrophy & 0.49 & $0.34-0.64$ & $\S$ \\
\hline Parkinson disease & 0.51 & $0.44-0.59$ & $82 \%$ \\
\hline Spina bifida & 0.66 & $0.57-0.76$ & $\S$ \\
\hline Spinal cord tumour & 0.60 & $0.44-0.77$ & $73 \%$ \\
\hline Stroke & 0.49 & $0.44-0.55$ & $79 \%$ \\
\hline Spinal cord injury (traumatic) & 0.41 & $0.35-0.47$ & $92 \%$ \\
\hline Tourette syndrome & 0.71 & $0.60-0.82$ & $\S$ \\
\hline
\end{tabular}

HUI $=$ Health Utilities Index; SLNCC $=$ Survey on Living with a

Neurological Condition in Canada.

*Source: Mapping Connections, Figure 1-6, page 23.

${ }^{\dagger}$ Disability categories indicated by HUI scores: 1 , none; $0.89-0.99$, mild; $0.70-0.88$, moderate; $<0.70$, severe. ${ }^{21,22}$

${ }^{\ddagger}$ Unpublished data from the Microsimulation Project report; published with permission of the Public Health Agency of Canada.

${ }^{\S}$ Data unreportable because of small sample size or high sampling variability.

"Alzheimer disease and other dementias.

this cohort revealed that children with a neurological condition obtained lower scores on a pediatric quality of life scale than children with other chronic conditions or without any of these conditions. About $33 \%$ of children with a neurological condition were considered by their parents to have "fair" or "poor" mental health, whereas the majority described their child's general health as good. Approximately $15 \%$ of children with a neurological condition were reported to be housebound, and nearly $50 \%$ required the use of assistive devices. Finally, more than $40 \%$ of parents in this cohort felt that their child had limited educational opportunities (Mapping Connections, Component $9^{5}$ ).

\section{Impacts on First Nations and Métis Populations}

In addition to the impacts experienced by other Canadians, First Nations and Métis Canadians face unique effects of neurological conditions related to spiritual needs and a lack of culturally relevant services (Mapping Connections, Component $11^{5}$ ). 
Table 6: Indirect economic costs* due to working-age death and disability for 7 neurological conditions, Canada, ages 15-74, Microsimulation Project ${ }^{\dagger}$

\begin{tabular}{l|c|c}
\hline & \multicolumn{2}{|c}{ Indirect costs $^{\ddagger}$} \\
\hline Neurological condition & $\mathbf{2 0 1 1}$ & $\mathbf{2 0 3 1}^{\$}$ \\
\hline Brain injury (traumatic) & $\$ 7,402,943,000$ & $\$ 8,218,317,000$ \\
\hline Cerebral palsy & $\$ 983,356,000$ & $\$ 1,138,034,000$ \\
\hline Demential & $\$ 607,453,000$ & $\$ 722,577,000$ \\
\hline Epilepsy & $\$ 2,577,840,000$ & $\$ 2,824,179,000$ \\
\hline Multiple sclerosis & $\$ 1,351,954,000$ & $\$ 1,455,728,000$ \\
\hline Parkinson disease & $\$ 258,848,000$ & $\$ 305,514,000$ \\
\hline Spinal cord injury (traumatic) & $\$ 505,102,000$ & $\$ 555,627,000$ \\
\hline
\end{tabular}

*Indirect costs calculated from average income lost from death or disability in the working-age (15-74) population.

†Source: Mapping Connections, Figure 1-9, page 31.

${ }^{\ddagger}$ Canadian $\$$, rounded to nearest 1,000 .

${ }^{\S}$ Projected indirect costs.

"Alzheimer disease and other dementias.

\section{Health Care Services for neurological Conditions}

The health needs of individuals with neurological conditions extend across the continuum of care. The study explored health services in terms of utilization, costs, and perceptions of adequacy.

\section{Utilization}

Canadians with a neurological condition used more health care services than those without a neurological condition (Table 7).

In British Columbia, for example, physician visits (Table 8), both in the community and in acute care hospitals, were 1.5 to 5.6 times higher, and prescribed medication usage, expressed as per capita days of dispensed medication (Table 9), was 1.7 to 5.8 times greater for those with a neurological condition compared to those without the condition in fiscal year 2010/2011. The use of prescribed medications was highest in British Columbia for those with parkinsonism and dementia (Table 9).

In British Columbia during fiscal year 2010/2011, average per capita acute hospital stays ranged from 2.2 days for women with multiple sclerosis to 64.7 days for men with a spinal cord injury (Table 10). Depending on the condition, such hospital stays were 3.5 to 110 times higher for individuals with one of 13 neurological conditions than for individuals without the neurological condition (Table 10).

The interRAI Project (Mapping Connections, Component $8^{5}$ ) found that individuals with a neurological condition awaiting nursing home placement also accounted for more days in alternate levels of care in acute care hospitals than those without neurological conditions. Dementia was the most common diagnosis of identified patients requiring alternate levels of care (approximately half), followed by parkinsonism (less than 10\%).

Depending on the condition, the number of days in residential care per capita was 3 to 197 times higher among individuals with a specific neurological condition than among those without that condition (Table 11). Individuals with Huntington disease had the highest number of days in such facilities-based continuing care.
Table 7: Health service utilization by Canadians with and without neurological or other chronic conditions, by health professional type, Canada, 2010-2012, LINC Project*

\begin{tabular}{l|c|c|c}
\hline & \multicolumn{3}{|c}{ Health services used in the past year (\%) by: } \\
\hline $\begin{array}{l}\text { Health } \\
\text { professional }\end{array}$ & $\begin{array}{c}\text { LINC } \\
\text { participants }^{\dagger}\end{array}$ & $\begin{array}{c}\text { Canadians with one or } \\
\text { more chronic } \\
\text { conditions }^{\dagger}\end{array}$ & $\begin{array}{c}\text { General } \\
\text { Canadian } \\
\text { population }\end{array}$ \\
\hline General practitioner & 90.8 & 91.2 & 80.7 \\
\hline Specialist & 65.5 & 48.2 & 33.4 \\
\hline Nurse & 36.3 & 18.4 & 12.4 \\
\hline Chiropractor & 84.6 & 83.6 & 87.4 \\
\hline Physiotherapist & 36.1 & 17.8 & 11.8 \\
\hline Psychologist & 15.4 & 8.6 & 4.3 \\
\hline $\begin{array}{l}\text { Social worker/ } \\
\text { counsellor }\end{array}$ & 20.7 & 10.1 & 4.9 \\
\hline Other therapists" & 18.4 & 5.1 & 3.3 \\
\hline $\begin{array}{l}\text { Mental health } \\
\text { consultant }\end{array}$ & 38.5 & 24.0 & 11.9 \\
\hline
\end{tabular}

LINC $=$ Everyday Experience of Living with and Managing a

Neurological Condition.

*Source: Mapping Connections, Figure 2-1, page 35.

${ }^{\dagger}$ Voluntary participants in the LINC Project survey.

${ }^{\ddagger}$ CCHS 2009-2010 data weighted to represent the Canadian population with other chronic conditions and age-sex standardized to the LINC population.

${ }^{\S}$ CCHS 2009-2010 weighted to represent the overall Canadian population and age-sex standardized to the LINC population.

"Occupational therapists, audiologists, and speech therapists.

Individuals with neurological conditions in registered home care programs, nursing homes, complex continuing care, or mental health facilities were also documented to have substantially more complex health and functional needs than their counterparts without a neurological condition in those settings (Mapping Connections, Component $8^{5}$ ).

Children living with a neurological condition were more likely to have a hospital stay, contact a specialist physician, receive mental health services, or consult with a social worker or counsellor, although they used generalist physician services at a level similar to Canadian children overall (Mapping Connections, Component $9^{5}$ ).

Formal assistance was used by $25 \%$ of respondents to the LINC Project survey and by $21 \%$ of those interviewed by the SLNCC Project (Table 12). In fiscal year 2010/2011, formal assistance was typically used in conjunction with care provided by family members, friends, and neighbours (informal care) and was used at least once a week. In 2011/2012, 47\% of Canadians with a neurological condition depended on informal assistance for care and support (Table 12).

The number of Canadians who will be candidates for informal care in the future ${ }^{24}$ and the total hours of informal care ${ }^{25}$ that will be required per week was estimated by microsimulation modelling. In 2011, the extent of informal care ranged from 17.9 to 73.6 hours per person per week for the seven neurological conditions investigated (Table 13). Depending on the condition, the total number of hours of informal caregiving for these 
Table 8: Physician visits, British Columbia, men and women, fiscal year 2010/2011*

\begin{tabular}{|c|c|c|c|c|}
\hline \multirow[b]{2}{*}{ Neurological condition } & \multicolumn{2}{|c|}{ Men } & \multicolumn{2}{|c|}{ Women } \\
\hline & $\begin{array}{c}\text { Visits per } \\
\text { capita }^{\dagger}\end{array}$ & $\begin{array}{l}\text { Rate } \\
\text { ratios }^{\ddagger}\end{array}$ & $\begin{array}{c}\text { Visits per } \\
\text { capita }^{\dagger}\end{array}$ & $\begin{array}{l}\text { Rate } \\
\text { ratios }^{\dagger}\end{array}$ \\
\hline Anterior horn cell disease $\mathrm{e}^{\S}$ & 50.1 & 3.0 & 49.2 & 2.3 \\
\hline Brain injury (traumatic) & 66.2 & 4.0 & 79.5 & 3.7 \\
\hline Brain tumour: malignant & 53.7 & 3.2 & 51.3 & 2.4 \\
\hline Cerebral palsy & 27.3 & 1.7 & 30.8 & 1.5 \\
\hline Demential" & 55.1 & 3.4 & 46.6 & 2.2 \\
\hline Epilepsy & 33.0 & 2.0 & 38.4 & 1.8 \\
\hline Huntington disease & 44.8 & 2.7 & 37.3 & 1.8 \\
\hline Hydrocephalus & 44.3 & 2.7 & 45.5 & 2.1 \\
\hline Multiple sclerosis & 34.4 & 2.1 & 38.0 & 1.8 \\
\hline Myopathy ${ }^{\text {g }}$ & 42.7 & 2.6 & 41.4 & 2.0 \\
\hline Parkinsonism ${ }^{\#}$ & 52.4 & 3.2 & 51.3 & 2.4 \\
\hline Spina bifida & 43.5 & 2.6 & 43.9 & 2.1 \\
\hline Spinal cord injury & 92.9 & 5.6 & 91.2 & 4.3 \\
\hline
\end{tabular}

*Source: Unpublished data from the Report of the BC Administrative Data Project (Mapping Connections, Component $1^{5}$ ); published with permission of the principal investigator.

"Inpatient and outpatient visits.

${ }^{\ddagger}$ Persons with a neurological condition/persons without the condition.

${ }^{\S}$ Includes amyotrophic lateral sclerosis.

"Alzheimer disease and other dementias.

"IIncludes muscular dystrophy.

\#Includes Parkinson disease.

conditions is projected to increase by $28 \%$ to $100 \%$ by 2031 (Table 13). Meeting the anticipated increase in demand for informal care may be particularly challenging given current sociodemographic trends in which families, whose members provide much of this care, are smaller and more dispersed geographically.

Informal caregiving is stressful and has financial costs. Distress was experienced by $28 \%$ of caregivers of individuals with a neurological condition in registered home care programs in Ontario and Manitoba, compared with $13 \%$ of caregivers of individuals without a neurological condition (Mapping Connections, Component $8^{5}$ ). In addition, among parents providing care for a child with a neurological condition, one-third had personally accessed mental health services and almost 35\% reported issues such as a financial crisis, a demotion or pay cut, or a limitation of their ability to work outside the home in the year before the survey (Mapping Connections, Component $9^{5}$ ). In 2011, average annual out-of-pocket costs for caregivers ranged from approximately $\$ 1.7$ thousand per individual with epilepsy to approximately $\$ 4.6$ thousand per individual with dementia (Mapping Connections, Component $10^{5}$ ).

\section{Health Care Costs}

During fiscal year 2010/2011 in British Columbia, total direct health care costs for 13 neurological conditions were 3 to 41 times higher among individuals with these conditions
Table 9: Dispensed prescription days, British Columbia, men and women, fiscal year 2010/2011*

\begin{tabular}{|c|c|c|c|c|}
\hline \multirow[b]{2}{*}{ Neurological condition } & \multicolumn{2}{|c|}{ Men } & \multicolumn{2}{|c|}{ Women } \\
\hline & $\begin{array}{l}\text { Days }{ }^{\dagger} \text { per } \\
\text { capita }\end{array}$ & $\begin{array}{c}\text { Rate } \\
\text { ratios }\end{array}$ & $\begin{array}{c}\text { Days per } \\
\text { capita }^{\dagger}\end{array}$ & $\begin{array}{r}\text { Rate } \\
\text { ratios }\end{array}$ \\
\hline Anterior horn cell disease $\mathrm{f}^{\S}$ & 1080 & 3.5 & 1278 & 3.2 \\
\hline Brain injury (traumatic) & 656 & 2.1 & 1198 & 3.0 \\
\hline Brain tumour: malignant & 747 & 2.4 & 941 & 2.3 \\
\hline Cerebral palsy & 769 & 2.5 & 918 & 2.3 \\
\hline Demential" & 1733 & 5.8 & 1898 & 4.9 \\
\hline Epilepsy & 886 & 2.9 & 1063 & 2.7 \\
\hline Huntington disease & 1349 & 4.4 & 1522 & 3.8 \\
\hline Hydrocephalus & 902 & 3.0 & 1056 & 2.6 \\
\hline Multiple sclerosis & 983 & 2.1 & 1062 & 1.8 \\
\hline Myopathy ${ }^{\text {Il }}$ & 843 & 2.8 & 876 & 2.2 \\
\hline Parkinsonism ${ }^{\#}$ & 1689 & 3.2 & 1953 & 2.4 \\
\hline Spina bifida & 560 & 2.8 & 667 & 1.7 \\
\hline Spinal cord injury & 864 & 1.8 & 689 & 1.7 \\
\hline
\end{tabular}

* Source: Unpublished data from the Report of the BC Administrative Data Project (Mapping Connections, Component $1^{5}$ ); published with permission of the principal investigator.

${ }^{\dagger}$ Number of days covered by dispensed medications.

${ }^{\ddagger}$ Utilization by persons with a neurological condition/utilization by persons without the condition.

${ }^{\S}$ Includes amyotrophic lateral sclerosis.

"Alzheimer's disease and other dementias.

"Includes muscular dystrophy.

\#Includes Parkinsons disease.

compared with costs for individuals without the condition (age-standardized) ${ }^{26}$ Direct costs for continuing care (home care and facility-based long-term care) from several other provinces were also shown to be greater for individuals with neurological conditions (Mapping Connections, Component $8^{5}$ ). Although these findings may not be fully representative of all provinces and territories, they provide useful information pertaining to a substantial proportion of the Canadian population.

Microsimulation modelling predicts that, if present trends continue, direct health care costs for individuals with dementia and those with Parkinson disease will double by 2031, whereas costs of the other five modelled neurological conditions will increase modestly. Acute hospitalizations are projected to be the largest contributor to these increased costs for all but dementia, where facilities-based long-term care will account for the largest proportion of direct costs.

In addition to high direct health care costs, nearly $20 \%$ of respondents to the LINC survey reported that they had paid more than $\$ 1,000$ in out-of-pocket expenses in the previous year. Sixty percent of the LINC survey respondents also reported out-of-pocket costs for prescribed medications, despite the fact that $85 \%$ of them had a drug insurance plan. In British Columbia (Mapping Connections, Component $1^{5}$ ); average out-of-pocket costs of medications not covered by Pharmacare were more than $\$ 1,000$ in fiscal year 2010/2011 for three neurological conditions: brain tumour, \$1,095 (age-standardized 
Table 10: Acute hospital stays, British Columbia, men and women, fiscal year 2010/2011*

\begin{tabular}{|c|c|c|c|c|}
\hline \multirow[b]{2}{*}{ Neurological condition } & \multicolumn{2}{|c|}{ Men } & \multicolumn{2}{|c|}{ Women } \\
\hline & $\begin{array}{c}\text { Days per } \\
\text { capita }^{\dagger}\end{array}$ & $\begin{array}{l}\text { Rate } \\
\text { ratios }^{\ddagger}\end{array}$ & $\begin{array}{c}\text { Days per } \\
\text { capita }^{\dagger}\end{array}$ & $\begin{array}{l}\text { Rate } \\
\text { ratios }^{\dagger}\end{array}$ \\
\hline Anterior horn cell disease ${ }^{\S}$ & 11.2 & 18.9 & 8.6 & 13.3 \\
\hline Brain injury (traumatic) & 20.0 & 34.6 & 23.6 & 37.0 \\
\hline Brain tumour: malignant & 9.6 & 16.2 & 8.1 & 12.6 \\
\hline Cerebral palsy & 2.6 & 4.4 & 2.4 & 3.8 \\
\hline Demential" & 10.2 & 21.1 & 7.4 & 14.0 \\
\hline Epilepsy & 2.7 & 4.7 & 2.7 & 4.3 \\
\hline Huntington disease & 8.9 & 15.0 & 12.2 & 18.8 \\
\hline Hydrocephalus & 8.1 & 13.8 & 6.2 & 9.6 \\
\hline Multiple sclerosis & 2.5 & 4.3 & 2.2 & 3.5 \\
\hline Myopathy ${ }^{\text {II }}$ & 4.3 & 7.2 & 5.5 & 8.5 \\
\hline Parkinsonism ${ }^{\#}$ & 7.1 & 12.4 & 6.5 & 10.2 \\
\hline Spina bifida & 6.5 & 11.0 & 3.0 & 4.6 \\
\hline Spinal cord injury & 64.7 & 109.5 & 52.1 & 80.5 \\
\hline
\end{tabular}

*Source: Unpublished data from the Report of the BC Administrative Data Project (Mapping Connections, Component $1^{5}$ ); published with permission of the principal investigator.

"Includes rehabilitation and day surgery.

${ }^{\ddagger}$ Length of stay for persons with a neurological condition/length of stay for persons without the condition.

${ }^{\S}$ Includes amyotrophic lateral sclerosis.

"Alzheimer's disease and other dementias.

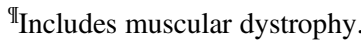

\#Includes Parkinson disease.

comparison group without the condition, \$313); multiple sclerosis, $\$ 1,270$ (comparison group, $\$ 311$ ); and parkinsonism, \$1,071 (comparison group, \$311).

\section{Health Care Limitations}

The Health Services Project (Mapping Connections, Component $7^{5}$ ) team interviewed care providers and policy-makers, and surveyed administrators of publicly funded acute care hospitals, long-term care facilities, and community outpatient centres across Canada. The main gap identified by this project was a lack of knowledge about neurological conditions among service providers.

Other projects documented limited availability and access to services. About one-third of respondents to the LINC survey reported access difficulties when seeking the services of a specialist. The scarcity of health services was particularly severe for those living in rural or remote areas and for those with rare neurological conditions.

Some factors that limited access to needed health services for those with neurological conditions included ratios of staff to clients, inadequate facilities, and limited mental health services, despite the documented need. ${ }^{27}$ The Health Services Project also found that more than $70 \%$ of facilities responding to its survey had exclusion criteria, mainly for psychiatric diagnoses, behavioral disorders or substance abuse (33\% of reporting facilities), medical instability or comorbidities (32\%), and age (21\%). Rehabilitation
Table 11: Residential care*, British Columbia, men and women, fiscal year 2009/2010 ${ }^{\dagger}$

\begin{tabular}{|c|c|c|c|c|}
\hline \multirow[b]{2}{*}{ Neurological condition } & \multicolumn{2}{|c|}{ Men } & \multicolumn{2}{|c|}{ Women } \\
\hline & $\begin{array}{c}\text { Days per } \\
\text { capita }\end{array}$ & $\begin{array}{c}\text { Rate } \\
\text { ratios }\end{array}$ & $\begin{array}{c}\text { Days per } \\
\text { capita }\end{array}$ & $\begin{array}{l}\text { Rate } \\
\text { ratios }\end{array}$ \\
\hline Anterior horn cell disease ${ }^{\S}$ & 44.1 & 34.7 & 49.9 & 18.6 \\
\hline Brain injury (traumatic) & 9.7 & 7.6 & 19.8 & 7.4 \\
\hline Brain tumour: malignant & 8.4 & 6.7 & 12.0 & 4.5 \\
\hline Cerebral palsy & 80.0 & 28.2 & 81.3 & 14.5 \\
\hline Demential" & 97.1 & 197.7 & 134.3 & 141.1 \\
\hline Epilepsy & 9.7 & 8.0 & 13.0 & 5.0 \\
\hline Huntington disease & 231.6 & 77.6 & 248.6 & 43.2 \\
\hline Hydrocephalus & 30.2 & 24.0 & 32.6 & 12.2 \\
\hline Multiple sclerosis & 28.0 & 22.4 & 19.2 & 7.3 \\
\hline Myopathy ${ }^{\text {Il }}$ & 11.3 & 8.9 & 23.7 & 8.8 \\
\hline Parkinsonism ${ }^{\#}$ & 50.5 & 44.3 & 76.1 & 30.1 \\
\hline Spina bifida & 7.4 & 5.8 & 8.4 & 3.1 \\
\hline Spinal cord injury & 19.6 & 15.3 & 14.2 & 5.3 \\
\hline
\end{tabular}

*Facilities-based continuing care.

${ }^{\dagger}$ Source: Unpublished data from the Report of the BC Administrative Data Project (Mapping Connections, Component $1^{5}$ ); published with permission of the principal investigator.

${ }^{\ddagger}$ Length of stay for persons with a neurological condition/Length of stay for persons without the condition.

${ }^{\S}$ Includes amyotrophic lateral sclerosis.

"Alzheimer disease and other dementias.

"Includes muscular dystrophy.

"Includes Parkinson's disease.

services were difficult to obtain if the neurological condition was long-standing (e.g. cerebral palsy) or combined with a cognitive impairment (Mapping Connections, Component $8^{5}$ ).

Gaps in support services, particularly for services regarding education or return to school, employment, housing, and transportation, were also highlighted by the Health Services Project. Furthermore, the service providers and policy-makers interviewed by this project team described the need for models of care that shifted the emphasis from diagnosis to functional requirements, a theme that was also highlighted by the interRAI Project (Mapping Connections, Component $8^{5}$ ). Limited services to address the needs of families and caregivers and to support transitions between health care settings (e.g. pediatric to adult, community to long-term care) were also identified. To address these limitations and special needs, the Health Services Project team developed a modified Chronic Care Model for Neurological Conditions. ${ }^{28}$ Although not yet validated, this model provides an interesting perspective for future consideration.

Fewer services are available for children (age 0 to 17 years) than for adults. The LINC Project survey of parents of children with neurological conditions found that one-fifth of the children had not seen a general practitioner or pediatrician in the previous year, and only two-thirds had received specialist physician care.

The Native Women's Association of Canada Project (Mapping Connections, Component $11^{5}$ ) reported that First Nations and Métis Canadians with neurological conditions face unique challenges in 
Table 12: Formal and informal assistance, Canada, 2011-2012, SLNCC*

\begin{tabular}{l|c|c}
\hline & \multicolumn{2}{|c}{ Proportion (\%) receiving: } \\
\hline Type of assistance & Formal care $^{\dagger}$ & Informal care $^{\ddagger}$ \\
\hline Any type of assistance & 21.2 & 47.0 \\
\hline Personal care & 48.6 & 40.4 \\
\hline Medical care & 35.7 & 39.4 \\
\hline Managing care & 19.6 & 57.2 \\
\hline Help with activities & 51.7 & 78.7 \\
\hline Child care & $\S$ & $7.6^{11}$ \\
\hline Transportation & 38.0 & 77.1 \\
\hline Meal preparation/delivery & 31.9 & 63.0 \\
\hline Emotional support & 35.2 & 81.3 \\
\hline Other assistance & $10.0^{11}$ & $2.5^{11}$ \\
\hline
\end{tabular}

SLNCC $=$ Survey on Living with a Neurological Condition in Canada.

*Source: Mapping Connections, Figure 2-2, page 36.

${ }^{\dagger}$ Care provided by health care workers.

${ }^{\ddagger}$ Care provided by family, friends, and neighbours.

${ }^{\S}$ Sample size too small to report.

"Interpret with caution; coefficient of variation between 16.6 and 33.3.

obtaining health services for neurological conditions, in addition to those faced by other Canadians. The project team concluded that overcoming these challenges would not only require increasing the availability of services in their often remote communities but also instituting holistic approaches to healing, providing opportunities for traditional ceremonies and gatherings, and making advocates or guides available to First Nations and Métis individuals when they encounter the health care system.

Overall, the study provides ample documentation of the extent, cost, and current limitations of the health care services for Canadians with neurological conditions. By highlighting these needs, some of which are presently unmet and/or projected to increase dramatically in the coming years, the study has identified challenges for the health care system that demand the attention of everyone from policy-makers and health care planners to frontline care providers. The findings related to utilization and costs are also a strong rationale for enhanced research and innovations for the prevention, early diagnosis, management, and organization of services for neurological conditions.

\section{KNOWLEdGe Gaps Identified bY THE STUdY}

In addition to the previously noted limitations of health care services for those with neurological conditions, the study identified gaps in knowledge pertaining to the following:

- Populations that are typically excluded from national surveys. For example, children younger than 12 years of age and most First Nations, Inuit, and Métis Canadians are not included in the CCHS.

- Canadians with less prevalent neurological conditions whose numbers, even in two years of CCHS data, were insufficient for complete analysis.

- Regional and jurisdictional variations in the distribution, quality, and costs of health services for those with a neurological condition.
Table 13: Hours of informal caregiving per week for 7 neurological conditions, Canada, ages $15+$, Microsimulation Project*

\begin{tabular}{l|c|c|c}
\hline $\begin{array}{l}\text { Neurological } \\
\text { condition }\end{array}$ & $\begin{array}{c}\text { Hours/week per } \\
\text { capita 2011 }\end{array}$ & $\begin{array}{c}\text { Total hours per } \\
\text { week 2011 }\end{array}$ & $\begin{array}{c}\text { Projected increase } \\
\text { by 2031 (\%) }\end{array}$ \\
\hline $\begin{array}{c}\text { Brain injury } \\
\text { (traumatic) }\end{array}$ & 17.9 & $5,973,190$ & 40 \\
\hline Cerebral palsy $^{\text {Dementia }}{ }^{\dagger}$ & 29.7 & $1,431,843$ & 28 \\
\hline Dpilepsy $^{\text {Multiple sclerosis }}$ & 73.6 & $19,235,612$ & 100 \\
\hline Parkinson disease & 23.2 & $1,950,742$ & 45 \\
\hline $\begin{array}{c}\text { Traumatic spinal } \\
\text { cord injury }\end{array}$ & 20.8 & $1,478,236$ & 55 \\
\hline
\end{tabular}

*Source: Mapping Connections, Figures 2-4, 2-5, pages 47, 48.

${ }^{\dagger}$ Alzheimer disease and other dementias.

- The clinical and public health relevance of potential risk factors for the onset and progression of neurological conditions.

- The potential effects of prevention strategies, earlier interventions, new treatments, or rehabilitation approaches on the future impacts of, and services for, Canadians with neurological conditions.

Identification of these knowledge gaps is expected to guide future research on neurological conditions.

\section{Conclusions}

Mapping Connections: An Understanding of Neurological Conditions in Canada - the report of the National Population Health Study of Neurological Conditions, contains new estimates of the prevalence of diseases, disorders, and injuries of the nervous system as well as comprehensive data on both the personal and societal impacts of these conditions and the related health service costs and utilization. The enhanced appreciation of neurological conditions provided by this information underscores several important conclusions that are relevant for health care providers and policy-makers:

- The disabilities caused by neurological conditions, many of which are chronic and progressive, frequently have significant negative impacts on those living with the conditions, the family members and friends on whom they depend for substantial portions of their care, the entire health care system, and society in general.

- The many commonalities of the impacts of neurological conditions on individuals as well as family and friend caregiversregardless of the specific diagnosis-should prompt collaboration and collective action to address shared challenges.

- Given present trends, the disability and economic impacts of neurological conditions will increase substantially over the next two decades, particularly for those conditions that mainly affect the elderly. - Demographic changes, such as the trends towards smaller and more dispersed families, could lead to limitations in the availability of the informal care that is so important for many Canadians with neurological conditions.

- Support for neuroscience research-both fundamental and applied-should be regarded as an urgent and essential 
investment by society to ameliorate the disability and economic impacts of neurological conditions.

The National Population Health Study of Neurological Conditions was the largest of its kind to have been undertaken in Canada. If its legacy increases awareness and understanding of neurological conditions and influences policy-makers, health service planners, and providers to reduce the impacts of neurological conditions and improve the quality of life of those affected, the study will have achieved its main objectives, and the collaborative effort that went into its planning and execution will have been justified.

\section{ACKNOWLEDGMENTS}

The authors thank Dr. Sulan Dai, Asako Bienek, and Catherine Pelletier of the Public Health Agency of Canada for their assistance with the preparation of this review.

\section{Disclosure}

Garth Bray and Deanna Huggett have nothing to disclose.

\section{REFERENCES}

1. Caesar-Chavannes CR, MacDonald S. Cross-Canada Forum: National Population Health Study of Neurological Conditions in Canada. Chronic Dis Inj Canada. 2013;33:188-91.

2. Neurological Health Charities Canada [Internet]. [cited 2015-12-10]. Available from: http://www.mybrainmatters.ca.

3. Public Health Agency of Canada [Internet]. [updated 2015-12-09; cited 2015-12-10]. Available from: http://www.phac-aspc.gc.ca/ cd-mc/nc-mn/ns-en-eng.php.

4. Government of Canada and Neurological Health Charities Canada. Mapping Connections: An understanding of neurological conditions in Canada. Ottawa (ON): Public Health Agency of Canada; 2014, Report No.: 140100. Available from: http://www.phacaspc.gc.ca/publicat/cd-mc/mc-ec/assets/pdf/mc-ec-eng.pdf.

5. Components of the National Population Health Study of Neurological Conditions, Appendix 1 in: Mapping Connections: An understanding of neurological conditions in Canada. Ottawa (ON): Public Health Agency of Canada, 2014, Report No.: 140100, pages 80-5.

6. Neurological Health Charities Canada [Internet]. List of peerreviewed publications resulting from the projects of the National Population Health Study of Neurological Conditions. Available from: http://www.mybrainmatters.ca/sites/default/files/ PublicationListNPHSNCFINALMar2015ENG\%282\%29.pdf.

7. Jetté N, Pringsheim T, principal investigators. Mapping Connections, Project [18]: Understanding the epidemiology of neurological conditions and building the methodological foundation for surveillance (Systematic Reviews Project). Webinar presented September 12, 2013. Available from: http://brainxchange.ca/Public/ Files/Events/National/Dr-Nathalie-Jette_NHCC-webinar.aspx.

8. Critically assessing new estimates of prevalence and incidence, in: Mapping Connections: An understanding of neurological conditions in Canada. Ottawa (ON): Public Health Agency of Canada, 2014, Report No.: 140100, page 52.

9. Prevalence of neurological conditions by data source, Table 3-1 in: Mapping Connections: An understanding of neurological conditions in Canada. Ottawa (ON): Public Health Agency of Canada, 2014, Report No.: 140100, pages 53-4.

10. Prevalence of neurological conditions among Canadians living in long-term care facilities, Table 3-2 in: Mapping Connections: An understanding of neurological conditions in Canada. Ottawa (ON): Public Health Agency of Canada, 2014, Report No.: 140100, page 55 .
11. Building capacity for the surveillance of neurological conditions is well underway, in: Mapping Connections: An understanding of neurological conditions in Canada. Ottawa $(\mathrm{ON})$ : Public Health Agency of Canada, 2014, Report No.: 140100, pages 63-5.

12. Microsimulation Models, Text-box in: Mapping Connections: An understanding of neurological conditions in Canada. Ottawa (ON): Public Health Agency of Canada, 2014, Report No.: 140100, page 11.

13. Projected incidence by select neurological condition, Table 3-7 in: Mapping Connections: An understanding of neurological conditions in Canada. Ottawa (ON): Public Health Agency of Canada, 2014, Report No.: 140100, page 68.

14. Projected prevalence by select neurological condition, Table 3-5 in: Mapping Connections: An understanding of neurological conditions in Canada. Ottawa (ON): Public Health Agency of Canada, 2014, Report No.: 140100, page 66.

15. Korngut L, Jetté N, Pringsheim T, Johnston M. Neurological registry best practice guidelines. Can J Neurol Sci. 2013;40(Suppl 2):S1-80.

16. Canadian Rett Syndrome Registry, [cited 2015-12-10]. Available from: http://www.rett.ca/registry/.

17. General health among respondents age $15+$ years living with a neurological condition, Figure 1-1 in: Mapping Connections: An understanding of neurological conditions in Canada. Ottawa (ON): Public Health Agency of Canada, 2014, Report No.: 140100, page 17.

18. Working status among respondents age 18 to 64 years living with a neurological condition, Figure 1-8 in: Mapping Connections: An understanding of neurological conditions in Canada. Ottawa (ON): Public Health Agency of Canada, 2014, Report No.: 140100 , page 25 .

19. Prevalence of impaired cognition among respondents age $15+$ years living with a neurological condition, Figure 1-3 in: Mapping Connections: An understanding of neurological conditions in Canada. Ottawa (ON): Public Health Agency of Canada, 2014, Report No.: 140100, page 20.

20. Prevalence of pain and discomfort among respondents age $15+$ years living with a neurological condition, Figure 1-5 in: Mapping Connections: An understanding of neurological conditions in Canada. Ottawa (ON): Public Health Agency of Canada, 2014, Report No.: 140100 , page 22.

21. Feeny DH, Furlong WJ, Torrance GW, et al. Multi-attribute and single-attribute utility functions for the Health utilities index Mark 3 system. Med Care. 2002;40:113-28.

22. Feng Y, Bernier J, McIntosh C, Orpana H. Validation of disability categories derived from Health utilities index Mark 3 scores. Health Rep. 2009;20:43-50.

23. Average number of years in full health lost due to disability and premature death, Table 1-1 in: Mapping Connections: An understanding of neurological conditions in Canada. Ottawa (ON): Public Health Agency of Canada, 2014, Report No.: 140100, page 29.

24. Projected number of Canadians who are likely candidates for informal care, Figure 2-4 in: Mapping Connections: An understanding of neurological conditions in Canada. Ottawa (ON): Public Health Agency of Canada, 2014, Report No.: 140100, page 47.

25. Projected number of hours of informal caregiving per week, Figure 2-5 in: Mapping Connections: An understanding of neurological conditions in Canada. Ottawa $(\mathrm{ON})$ : Public Health Agency of Canada, 2014, Report No.: 140100, page 48.

26. Direct health care costs by select neurological conditions, Table 2-1 in: Mapping Connections: An understanding of neurological conditions in Canada. Ottawa (ON): Public Health Agency of Canada, 2014, Report No.: 140100, page 39.

27. Prevalence of mood disorders among respondents age $15+$ years living with a neurological condition, Figure 1-2 in: Mapping Connections: An understanding of neurological conditions in Canada. Ottawa (ON): Public Health Agency of Canada, 2014, Report No.: 140100 , page 18.

28. Jaglal SB, Guilcher SJT, Bereket T, et al. Development of a chronic care model for neurological conditions (CCM-NC). BMC Health Serv Res. 2014;14:409. 